\title{
Actual problems of terminological system development of new state administration
}

\author{
Galina Anatolievna Zavarzina ${ }^{1, *}$, and Tatyana Nikolaevna Dankova ${ }^{2}$ \\ ${ }^{1}$ Voronezh Sate Pedagogical University, Russian language, modern Russian and foreign literature department,39400 Voronezh, Russia \\ ${ }^{2}$ Voronezh State Agricultural University, Russian and foreign language department, 39400 Voronezh, Russia
}

\begin{abstract}
This article is devoted to the study of the specific development features of a terminological state administration system, which is a combination of special phenomena and concepts from the sphere of public authorities activity and it is an integral part of the social and political term system. The dynamic development of the terminological system is caused by the intensive development of the Russian state and it is related primarily to the expansion of its composition due to the terms that are different in structure, semantic organization and the type of terminological name, as well as in the degree of formation and adaptation in the Russian language. It has been established that lexical items in the terminological system of state administration are forming new synonymous relations indicating three areas of language change: the occidentalisation of the Russian state administrative language, the actualization of nominations reflecting the realias of pre-revolutionary and Soviet reality, and also the fixation and the use of original names. It is concluded that the problem solution of the investigated term system development is important not only for the modern Russian language and the modern Russian national consciousness, but also for the effective government of the state.
\end{abstract}

\section{Introduction}

The attention of national and foreign linguistics to the formation and development problems of various terminological systems is caused by the importance of the linguistic term category and its active participation in the production, accumulation, synthesis and socialization of knowledge about the essence of things, phenomena, processes in nature, society and thinking that has undergone significant qualitative and quantitative changes. A new vector of scientific research has been formed in modern sociocultural conditions, accompanied by global informatization processes, conceptual integration and the adoption of a new, synergistic type of thinking. It is formed from semiotics to socially oriented terminology as a means of encoding and decoding new knowledge. It should be emphasized that at this stage of terminology development, a great scientific interest is raised by the questions of Russian terminologies dynamics, the basic laws of their formation, the definition of nominative processes in various sublanguages [6].

One of the dynamically developing term systems of the Russian language of the newest period is undoubtedly a very extensive government terminological system, which is a combination of special phenomena and concepts from the sphere of public authorities activity and it is an integral part of the social and political term system.

\section{Materials and methods}

The terminological units of the public administration sphere are the material for the study, they are presented: a) in various modern lexicographic sources (Russian language definition dictionaries, dictionaries of foreign and new words, general and special encyclopedic dictionaries), b) in the scientific and educational literature on political science, state and municipal (administrative) management, theory of public administration, political management; c) in the modern Internet discourse devoted to the Russian government administration (www. kremlin.ru, president. rf, putin. rf, government. rf, large government. rf, www.ar.gov.ru, etc.). To study the material, we have used methods of linguistic observation and description, methods of component, comparative, lexicographic and complex analysis as well as elements of the statistical method.

\section{Results}

The main study result is the proof of the dynamic development process of the Russian terminological system of the new public administration, which is accompanied by the complication of its structural and semantic organization and the consistent enrichment of the terminological world picture.

\footnotetext{
* Corresponding author: zga1311@mail.ru
} 


\section{Discussion}

From the point of view of structural and grammatical characteristics, the terms of the new state administration are represented by term-words (or uniterms) and terminological phrases (or quasiterms) [8,11].

Term-words of the analyzed sphere are represented by non-derivatives (e.g., department, president, duma, prime minister, speaker, mayor, etc.), derivatives (e.g, lack of alternatives, elective, state employee, subdelegation, pro-government, declare, etc.) and complex (e.g., business elite, plenipotentiary, cabmin, gosbudget, gorduma, Minoborony and etc.) nominations.

Terms abbreviations should also be referred to this structural type (e.g., EOP - executive office of the President, PC - public chamber, ASI - Agency for Strategic Initiatives; compare also: MinSelkhoz, TransMin, FinMin, Rostechnadzor, Roscosmos and others.).

Modern terminological studies confirm the fact that the formed term system of any field of knowledge contains about $70 \%$ of the term-phrases [7]. At the same time, multi-component terms in the term system of the new state administration can be two-word, three-word, and multiword (consisting of four or more components).

Two-word term phrases are presented, as a rule, by substantive terminological units building according to the following grammatical patterns: 1) noun + adjective (e.g., hardware ethics, administrative barrier, social explosion, non- budgetary fund, military doctrine, social infrastructure and others), 2) the noun in the nominative case + the noun in the indirect case (e.g., the governor's veto, branches of government, separation of powers, war of laws, vote of censure, institute of citizenship, and others). The predominance of nominal term phrases over verbs in the terminology of the new state administration is caused by more distinct systematizing properties and the principal ability to fill hyponymic positions in terminological microsystems.

Two-component term phrases can be reduced to two main types - free and non-free. In free phrases, each of the components is a term or it is motivated by a term, and their components can come into a two-way relationship (e.g., executive power, state administration, deputy minister, legislative initiative, party of the state, etc.). In non-free phrases, all components or one of them can be nonterminal (e.g., double standard, city council, state pocket, etc.).

Some resarchers among the term phrases distinguish the third tructural type of terminological nominations symbolic words, which include certain symbols (graphic signs or numbers) (e.g., concept - 2020; government 2.0; government 3.0. and etc.).

Three-component term phrases are built according to the type of concord as the main types of syntactic relation and they are represented by the following highly productive models: 1) noun + adjective + noun (e.g., institute of presidential power, head of local administration, readiness to the information society, local government bodies, failures of state regulation, etc.), 2) adjective + adjective + noun (e.g., new election technologies, multi-member electoral district, common economic space, central election commission, state electoral policy, etc.), 3) adjective + noun + noun in an indirect case with or without a preposition (e.g., State Statistics Committee, power structure of the government, Federal Security Service, Presidential Plenipotentiary Envoy, etc.).

As mentioned above, the term phrases in the terminology of the new state administration can consist of four or more components (e.g., the Ministry of the Russian Federation for Civil Defense, Emergencies and Disaster Relief; the Federal Fund for Financial Support of Russian Regions; Presidential Address to the Federal Assembly; marketing concept of public administration, etc.).

The processes of new concepts occurrence of the management sphere and the necessity for their differentiation are the objective conditions for the creation and functioning of multiverb terms that are striving for the extremely precise naming unit of this concept. Such special lexemes realize various term formative grammatical models and represent a plan for expressing derivational relations between terms. It should be emphasized that the term words and term phrases should be considered as single-level special nomination units from a functional point of view.

According to the study, the core of the new state administration terminology is nouns because of their categorical and syntactic features associated with the semantic objectivity and absolute use. In reality, the basic category of terminology in terms of speech part is the noun, which emphasizes the static element of the vocabulary, its constant essence.

The second most important terminology grammatical category of the new state administration is the adjective, which can only act as the term element of the compound term. The adjective can have the semantic load of the nominee as a grammatically dependent component in adjective terminological phrases. Many researchers believe that adjectives, participles, and other parts of speech can act as elements of the compound term, being part of the terminological phrase, but have no independent terminating meaning (if you exclude cases of substantivization) $[4,5]$.

When the grammatically supporting word is a general scientific term or a general literary language word, an adjective acts as a semantic specifier, creating on the basis of the term (management, power, law, parliament) its own terminological unit (e.g., managerial decision, authoritative powers, legal representative in law, parliamentary control and etc.).

In the role of term-components, general literary adjectives that are not motivated by their own terms (e.g., manual control, open society, upper chamber and etc.) and which realize non-free co-occurrence can also be used; the second component of such a term-phrase is usually its own term. Such terminologized adjectives lose quality or link semantics and acquire qualifying semantics, refining and narrowing the semantics of the new term in the direction of subsumption concretization.

In the terminology of the new state administration, we can also distinguish the term phrases of the verb (e.g., include into budget, impeach credibility, put 
before, declare income, etc.) and adverbial (e.g., on a long-term basis, on an ongoing basis, at the level, in mode, targeted, etc.) nature.

According to the terminological name type the term units of the new government are presented by: 1) general scientific terms that relate to objects, processes or properties of different scientific fields and represent nominations defining special concepts of a wide profile (e.g., study, review, approach, method, system, structure, element; direct, explore; received, determined, etc.), 2) inter-scientific terms functioning in several related terminological systems (e.g., marketing, management, manager, re-engineering, outsourcing, market - in economic and finance sphere; portal, blog, Internet, digital, network, virtual - in computer sphere; service, client, rebranding, public relations campaign- in the sphere of service and advertising; mono-city, tech city, innovation, nanotechnology - in the scientific and technical sphere, etc.), 3) highly specialized terms defining specific realities, phenomena and concepts of the scientific field under study (e.g., factionalist, parliament, speaker, constitution, deputy minister, etc.). The presence of a large number of inter-scientific terms in the economic, computer, and other spheres of public life indicates the penetration of term system borders and openness.

The study has showed that the terms of state administration can be modern, outdated and new nominations according to origin time and chronological status.

Outdated naming units are usually represented by: 1) historicism terms, in other words, verbal signs that have fallen out of use due to the disappearance of the realities, phenomena or concepts they designate (e.g., the dictatorship of the proletariat, the party leadership line, seven-year plan, socialist obligation, etc.); 2) archaism terms, that is, obsolete verbal signs, which have received new terminological name (e.g., militia - police, policeman - police officer, Ministry of Education and Science - Ministry of Education and the Ministry of Science and Higher Education; State Road Safety UnitGeneral Administration for Traffic Safety, etc.).

This phenomenon reflects the process of modifying old resources and creating new linguistic-terminological ones which are necessary for cultural and spiritual communication and allowing the enrichment of the social and language human community memory.

According to the analysis of factual material, neologisms form a quantitatively significant group of words in the term state administration system in relation to origin time. They stand for the nomination of new realities, phenomena and concepts or for new names of previously known realities, phenomena and concepts. The named group includes various types of so-called "strong lexical innovations", presented in accordance with the semantic theory of prof. O.V. Zagorovskaya by: 1) foreign language borrowed words that are utilized verbal marks (e.g., new state administration, new state management, effective administration, compound government, etc.) and unutilized terminology, nonadapted to the Russian language system in terms of pronunciation, spelling or grammatical characteristics (e.g., electronic government/ e-government/ $e$ Government/ eGovernment/ e-Gov; electronicadministration/ e-Administration/ eAdministration and etc.); 2) language signs created in the Russian language system (e.g., narrow institutional interests, sovereignization, to administrate, depoliticization, State Duma, beneficiary of funds, apparatchik, spending unit, social sphere in the sense of "social order", networker in the meaning of "representative of political networks", parliamentary-governmental, presidential-premieral, etc.).

In the contest of organization and special aspects of the semantic structure, the terms of public administration, as a rule, are synonymous special names, however, there are also polysemantic nominations formed, first of all, due to different types of semantic transfers (e.g., duma -1) the name of some legislative institutions of the Russian Federation; people who are members of such institutions; the building where the institution is located; 2) State Duma; Regionnaire - 1) a representative of the regional government; 2) a member of the deputy group; envoy's office - 1) a form of governing regions of the state through Plenipotentiary Representatives; authority of such management; 2) the place of envoy; his activities; the tenure of an envoy; compare: separation of powers - 1) separation of legislative, executive and judicial powers; 2) separation of powers between the central and regional authorities, etc.). The complexity of the semantic word structure can act as a term-formative formant (e.g., the system - about power structures that control the state life; about people having the power; the sector in the meaning of "state activity").

A special group of polysemic terms is formed by terminological metaphors (it should be noted that metaphorical and metonymic meanings in terms are often interlinked; compare: portfolio in the meaning of "a set of plans and instructions of the government"; portfolio in the meaning of "a set of state decisions, laws, documents, which is holistic in nature") and their typological properties should be reasoned by the degree of their correlation with the intentional meaning of the generative word. At the same time, terminological metaphorization can be defined as a metaphorical process that takes place in the sphere of the term creation and which is associated with the verbalization of scientific knowledge in the form of its conceptualization, complex and contradictory in its basis [2].

According to the degree of formation and adaptation in the Russian language, the terms of the new state administration can be represented by: 1) actual terms that stand for nominating stable concepts that have been completely formed in a particular field of scientific knowledge and they are distinguished by semantic certainty and identity of interpretation definitions in different lexicographical publications (e.g., state administration, ministry, government, president, etc.), 2) pre-terms - multiword (often quite long) nominations used as terms for naming new, recently formed or still forming concepts, typically borrowed from other cultures, and different in instability values and etc. $[1,3]$. Among the terms of a complicated nominative structure 
in the term system under study, it seems appropriate to single out: pre-terms - descriptive constructions, which are a multi-component nominative phrase that is used for designation and accurate description of a phenomenon or concept of the new state administration (e.g., an elective officer of local administration, agitation on grounds of the recall of a deputy, analytical departmental specialpurpose program, growth dynamics of the elective legal society culture, public service of the constituent entity of the Russian Federation and etc.); pre-terms coordinative phrases (e.g., defects and deformation of voters' consciousness, Public Services Portal of the Russian Federation, unified register of legal acts and other documents of the CIS and etc.); pre-terms combinations containing a participial construction (e.g., a document verifying the passport of a citizen; a voter being disabled; a person replacing a public office, etc.). Of course, pre-terms are temporary in nature and subsequently they are lost or pass into the category of terms.

Term lexems in the terminological system of state administration are forming new synonymic links (e.g., public government - public administration - public management; prime minister - chairman of the government- head of the government; mayor - head of city administration - city administrator; speaker chairman of the upper chamber of the Federal Assembly - chairman of the Federation Council - chairman of the State Duma - chairman of the lower chamber of the Federal Assembly, etc.).

Let us compare the use of synonymous terms for the name of the authorities of the Russian Federation subjects: Parliament - State Council - State Assembly People's Assembly - People's khural - Legislative Assembly - Supreme khural - Supreme Soviet. New synonymous links formation indicates the term system dynamic development of state administration and three vectors of transformations, manifested in the occidentalization of the Russian state-administrative language, in the actualization of nominations reflecting the realias of pre-revolutionary and Soviet reality, and also in fixing and using original names.

\section{Conclusion}

The study suggests that the development features of the modern Russian terminological system of the new state administration are caused by the intensive development of the Russian state and are characterized by national and cultural specifics. At the same time, the dynamics of term system development reflects the dynamics of scientific knowledge, which is expressed by a phased structure building up and complication of the studied term system and by the consistent enrichment of the terminological worldview. The study of the features and patterns of terminology formation and development of the new state administration term system is very essential for developing recommendations for improving and effectively using in human activity as an object and subject of management in the research field.

The work was supported by the RFBR Grant together with the constituent entities of the Russian Federation No. 18-412360006 p_a.

\section{References}

1. M.T.Cabré Castellví, Terminol, 9, 163 (2003)

2. M.T.C. Castellví, R.E. Bagot, C.V. Sierra, Terminol. Internat. J. of Theoret. \& Appl. Iss. in Spec. Communic, 18, 1 (2012)

3. B. Daille, Internat. Sumr. Sch. on Inform. Extr, 29 (2002)

4. K. Kageura et al., Terminol. Internat. J. of Theoret. \& Appl. Iss. in Spec. Communic, 10, 1 (2004)

5. K. Kageura, Handbk. of Terminol, 1, 45 (2015)

6. K. Kageura, The quantitative analysis of the dynamics and structure of terminologies (John Benjamins Publishing, Amsterdam, 15, 2012)

7. M.C. L'Homme, U. Heid U, J.C. Sager, Terminol. Internat. J. of Theoret. \& Appl. Iss. in Spec. Communic, 2,151 (2003)

8. N. Loukachevitch, B. Dobrov, Terminol. Internat. J. of Theoret. \& Appl. Iss. in Spec. Communic, 21, 237 (2015)

9. S.B. Grinev-Grinevich, Terminology (Academia, Moscow, 2008)

10. T.N. Dankova, O.V. Zagorovskaya, Problems of modern terminology (VSAU, Voronezh, 2018)

11. G. A. Zavarzina, Lang.\& Cultr, 25, 14, (2004) 